\title{
The national database of the German Collaborative Arthritis Centres: I. Structure, aims, and patients
}

\author{
A Zink, J Listing, C Klindworth, $\mathrm{H}$ Zeidler, for the German Collaborative Arthritis Centres*
}

\begin{abstract}
Objective-To describe the aims, principles, and content of the German rheumatological database and to present data on patient mix and healthcare provision for the year 1998.
\end{abstract}

Methods-The German rheumatological database contains clinical and patient derived data of the outpatients with inflammatory rheumatic diseases seen at one of the 24 collaborative arthritis centres. The case mix, institutional context, and demographic features of $25653 \mathrm{pa}$ tients from the year 1998 were analysed.

Results- $51 \%$ of the patients had rheumatoid arthritis, $23 \%$ seronegative spondyloarthropathies, including ankylosing spondylitis, psoriatic arthritis, and reactive arthritis, and $19 \%$ had vasculitis, including SLE (5\%). The distribution of the age at onset of patients with RA with $\leqslant 2$ years' disease duration was comparable with recent incidence data from population studies. The case mix differed between university departments and rheumatology hospitals as well as individual practices. $65 \%$ of the male and $46 \%$ of the female patients at ages 18-60 were still in gainful employment, the rates of employment were $14 \%$ below the population rates for women, and $11 \%$ below those for men. $62 \%$ of all patients had seen a rheumatologist within the first year of disease, $73 \%$ within the first two years. Ankylosing spondylitis was seen in rheumatological care much later than all other diseases (only 39\% within the first year). The mean number of contacts with a rheumatologist was five a year; rheumatologists in individual practices saw their patients seven times a year on the average. Together with visits to the non-specialist doctor mainly treating the patient, the mean number of visits to the doctor for a rheumatic condition was 20 a year.

Conclusion-Large databases like this one give information about the patient case mix in different healthcare settings, about treatment practice, and about the consequences of disease. Patients treated in specialised rheumatology units in Germany are referred earlier than in the past, which probably reflects better regional cooperation due to the implementation of arthritis centres. University departments and outpatient clinics of rheumatology hospitals contribute considerably to the specialised care of patients with arthritis and connective tissue diseases.

(Ann Rheum Dis 2001;60:199-206)

The general goal of clinical databases is to gather information on the processes of health care and the long term outcome of patients. They provide information about the case mix in various institutional settings, the provision of care in different groups of patients, and the disease course in unselected patient groups under regular - that is, non-trial, conditions. They also provide information about practice variation in health care. Moreover, as they include all patients treated in the given institutions within a specific time period, they are ideal sources for the selection of random samples of patients for clinical studies.

After the second world war, rheumatology in Germany developed primarily in nonuniversity rehabilitation clinics in spa towns. With the increasing availability of effective treatments and the rising awareness of the social and economic impact of inflammatory rheumatic diseases, these hospitals reached a high level of quality. In addition, since 1981 there has been a subspecialisation in rheumatology open to specialists in internal medicine and orthopaedics. It was, however, only in the 1970s that rheumatology became part of the standard education of medical students and even today not every medical school has chairs or permanent positions in rheumatology. Owing to this late and incomplete introduction of rheumatology into the university medical curriculum, there is a shortage of rheumatologists in individual practice. At present, Germany, with a population of 80 million, has about 400 rheumatologists whose origins are in internal medicine; half of them work in individual rheumatology practices. Owing to the shortage of rheumatologists in individual practice, rheumatologists working in hospitals also participate in outpatient care.

Outpatient care in Germany is mainly performed by doctors in individual fee for service practices. Most of the patients have a general health insurance; only about $8 \%$ are privately insured. People with joint problems usually first contact a general practitioner or specialist in internal medicine or orthopaedics without rheumatological subspecialisation. This primary care doctor decides whether he treats the patient alone or refers him to a rheumatologist in individual practice or to a rheumatology outpatient clinic at a general hospital, rheumatology hospital, or university. 


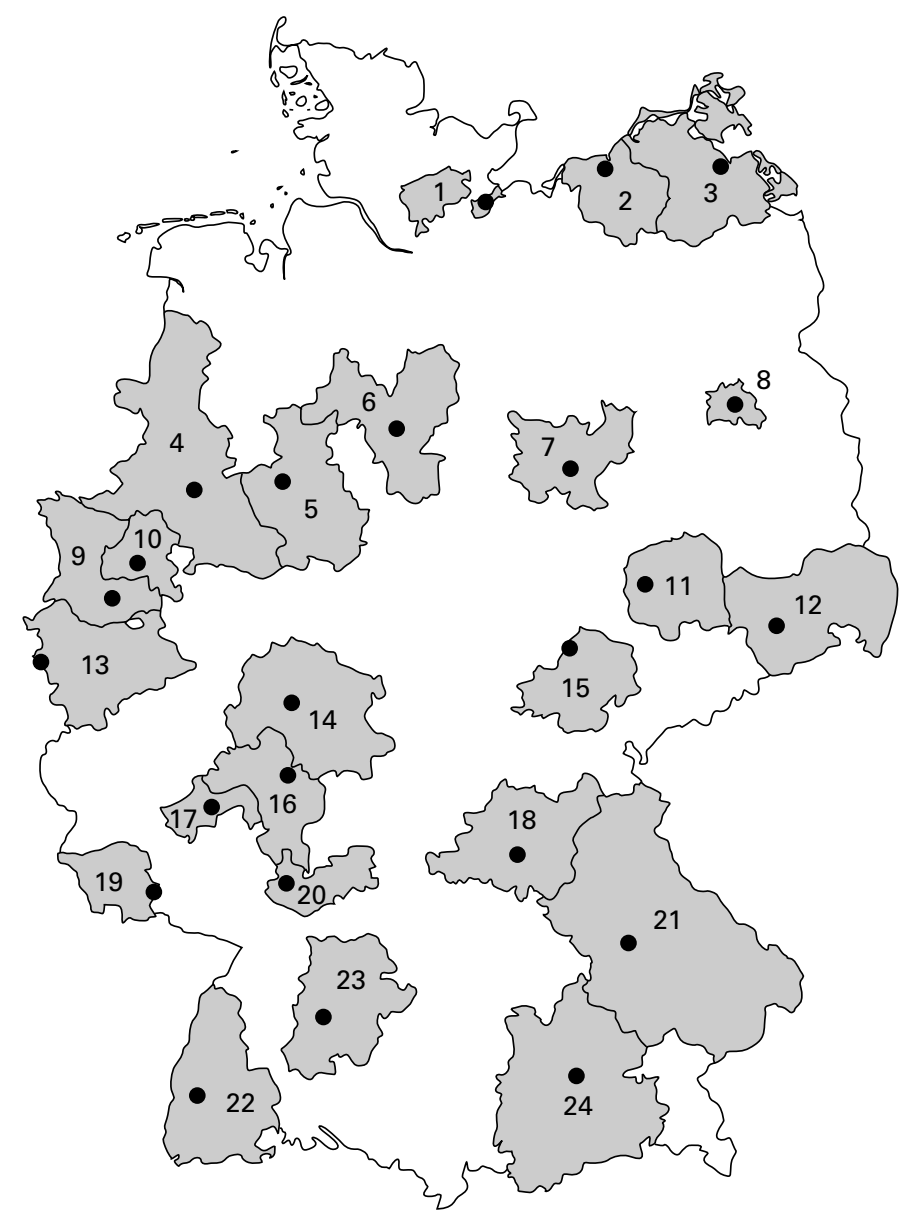

\begin{tabular}{|c|c|c|c|}
\hline 1 & Lübeck & 13 & Aachen/Köln/Bonn \\
\hline 2 & Rostock & 14 & Giessen \\
\hline 3 & Greifswald & 15 & Jena \\
\hline 4 & Münster & 16 & Rhein-Main (Frankfurt) \\
\hline 5 & Ostwestfalen (Bielefeld) & 17 & Rheinland Pfalz (Bad Kreuznach) \\
\hline 6 & Hannover & 18 & Erlangen \\
\hline 7 & Magdeburg & 19 & Saarland (Homburg) \\
\hline 8 & Berlin & 20 & Heidelberg \\
\hline 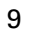 & Düsseldorf & 21 & Regensburg \\
\hline 10 & Westl. Ruhrgebiet (Essen) & 22 & Südbaden (Freiburg) \\
\hline 11 & Leipzig & 23 & Südwürttemberg (Tübingen) \\
\hline 12 & Dresden & 24 & München \\
\hline
\end{tabular}

Figure 1 Participating German Collaborative Arthritis Centres and their catchment areas.

Patients are allowed to contact a rheumatologist in individual practice directly, whereas they cannot go to an outpatient clinic without referral.

In the past, the German government has funded programmes to develop improved forms of outpatient care in rheumatology. One recent programme is the implementation of 24 so-called Regional Collaborative Arthritis Centres. ${ }^{1}$ These centres comprise rheumatologists with a background in internal medicine or orthopaedics at universities, non-university hospitals, or in individual practices. Figure 1 shows the locations and catchment areas of the arthritis centres. To evaluate the health service situation and the outcome of patients with inflammatory rheumatic diseases who are undergoing rheumatological care, the arthritis centres established a uniform core documentation of all their outpatients in $1993 .^{23}$

\section{Patients and methods}

PARTICIPATION

From their start in 1993 all arthritis centres supported by the Federal Ministry of Health were obliged to participate in the register in order to receive funds. This means that in the participating outpatient clinics and individual rheumatology practices each patient with an inflammatory rheumatic disease seen in routine outpatient care was documented once a year with a standard clinical record form and patient questionnaire.

A total of 71 units enrolled their outpatients in 1998, among them 20 university departments in internal rheumatology, two university departments in orthopaedic rheumatology, 19 departments of rheumatology at general hospitals or hospitals for rheumatic diseases, five rehabilitation hospitals (formerly, spa clinics), and 25 rheumatologists in individual practices.

The database comprises newly referred as well as prevalent cases. Patients seen regularly are registered once a year, if possible in the same month or at least the same quarter of the year as the year before. For these patients the same kind of information is available for successive years.

The rheumatologists are supposed to register every outpatient with an inflammatory rheumatic disease except those who refuse to participate. In addition, inpatients as well as patients with osteoarthritis, soft tissue disorders, or back pain are recorded by some of the centres for their own study purposes. The following analyses are restricted to outpatients with inflammatory rheumatic diseases.

\section{CONTENTS OF THE CLINICAL DOCUMENTATION} AND THE PATIENT QUESTIONNAIRE

The clinical datasheet contains demographic data of the patient (age, sex, insurance), onset of symptoms, onset of treatment in the institution, and up to three diagnoses made by the rheumatologist. The rheumatologists are asked to make their diagnosis in accordance with agreed classifications, which means that the diagnosis - for example, of rheumatoid arthritis (RA), is based upon the doctor's clinical judgment but is only recorded as "definite" if the American College of Rheumatology criteria $^{4}$ are met. All other cases are recorded as "suspected". Treatments (disease modifying antirheumatic drugs, non-steroidal antiinflammatory drugs, corticosteroids, osteoporosis treatment as well as physiotherapy and occupational therapy) are reported as "current treatment" (day of registration) and "treatment within the previous 12 months". The type of surgery is recorded as "within the previous 12 months" and "ever before". The doctor gives a global assessment of the present disease activity (based on a numerical rating scale from 0 to 10) and the severity of the disease (based on a five item Likert scale). The Steinbrocker functional class is used in a modified form 
(intermediate values I to II, II to III, III to IV are allowed). ${ }^{5}$ These ratings by the doctor of activity, severity, and function give global information of the doctor's judgments on the patient's condition. For patients with RA, 28 -joint counts ${ }^{6}$ for swollen and painful joints as well as erythrocyte sedimentation rate and $\mathrm{C}$ reactive protein are recorded by the doctor. This allows a 28-joint count disease activity score (DAS $28^{7}$ ) to be calculated.

The diagnoses are registered using a list of 190 diagnoses of the musculoskeletal system which was developed by a subcommittee of the German rheumatological association before the implementation of the database. Eighty of these diagnoses are indications of inflammatory rheumatic diseases. This list is more specific and detailed than the International Classification of Diseases (ICD), but all diagnoses based on it can be transformed into ICD-9 or ICD-10 codes by a unified dictionary developed by a consensus group.

The patients complete a self administered paper and pencil questionnaire. They give their treatment histories: onset of symptoms, first visit to a rheumatologist, number of visits to the primary doctor within the previous three months, and visits to the rheumatologist in the previous year. For the time window of 12 months the patients record their stays in hospitals or rehabilitation clinics, inpatient and outpatient treatment, including physiotherapy, balneotherapy, occupational therapy, psychological support, patient education, etc. Other items ask about self help, social support, degree of help needed as well as days of sickness or absence from work. The patients record their current pain and global function (previous seven days) on numerical rating scales (0-10) and their global wellbeing on a five item scale. Disability is recorded using an 18 item scale, the Hanover Functional Status Questionnaire $(\mathrm{FFbH})$, which measures limitations in various activities of daily living. The $\mathrm{FFbH}$ is similar to the HAQ (Health Assessment Questionnaire) but more widely used in Germany. The two disability scales are highly correlated $(r=0.87)$. $\mathrm{FFbH}$ values can be transformed into HAQ values. ${ }^{8} 9$ Demographic data of the patients are recorded on a standard form corresponding to the official health statistics.

The privacy of the patients is ensured by the coding of all data.

The core dataset used in this database has been widely accepted in Germany and all participants have agreed to integration of its items into all clinical documentation for use in cohorts and clinical trials.

DATA COLLECTION

Governmental funds are provided for the establishment of the position of a coordinator in every arthritis centre. These coordinators, usually rheumatologists, are also responsible for supervision of the documentation. This includes checks for completeness of case notification in the participating units. A second person, usually a student, is funded for study monitoring and is responsible for the completeness and validity of the data. Data entry is performed centrally by a professional company. As independent double data entry is performed, data entry errors are very low $(<0.2 \%)$. All centres are provided with their own data files and with support for individual analyses. The study group at the German Rheumatism Research Centre regularly runs workshops to train coordinators and students in study monitoring and data analysis and provides the centres with programs for data control and analysis. Validity checks are included in this software. After the local datasets have been tested and corrected, the data are sent to the group in Berlin for a comprehensive, centralised analysis. Here the data are checked again, and reminders on missing data are sent out. The centres are obliged to complete the data at least for age, sex, disease duration, and diagnosis, but it is not possible to obtain data missing from a patient questionnaire.

The datasheets are a different colour each year to facilitate discrimination between different years.

\section{STATISTICS}

The program SPSS (Statistical Package for the Social Sciences) ${ }^{10}$ is used for data entry and analysis.

This paper is based on data from the latest year available (1998). For the figure "age at onset" we used cumulative data of the years 1993-98 to increase the number of cases in each age group. To avoid bias due to memory or selective mortality and to ensure that diagnoses were made according to current criteria, we restricted our attention to patients with less than five years' disease duration in the age at onset figure.

The disease duration at the first visit to a rheumatologist or a family doctor shows a heavily skewed distribution owing to a small number of cases with a very long delay. In these analyses we used the 5\% trimmed arithmetic mean ${ }^{11}$ in addition to the median.

\section{Results}

In this article we describe the case mix and aspects of the healthcare situation of outpatients treated in the arthritis centres in 1998.

\section{DIAGNOSES, AGE, AGE AT ONSET}

In 25653 patients with inflammatory rheumatic diseases, the most common diseases were 12992 (51\%) RA, of whom 8104 (62\%) had a positive rheumatoid factor; 2119 psoriatic arthritis; 1486 ankylosing spondylitis (AS); 1524 "other seronegative spondyloarthropathies", 1211 systemic lupus erythematosus (SLE); and 998 polymyalgia rheumatica (table 1). "Other connective tissue diseases" comprised 12 diagnoses, such as mixed connective tissue disease, Wegener's syndrome, dermatomyositis and polymyositis, and connective tissue diseases otherwise not classifiable. "Other arthritides" comprised arthritis associated with colitis, Crohn's disease, sarcoidosis, etc.

For the most important diagnostic groups, table 1 shows the age and sex distribution, age 
Table 1 Characteristics of the outpatients in the database

\begin{tabular}{|c|c|c|c|c|c|c|}
\hline & No of cases & $\begin{array}{l}\text { Definite disease } \\
(\%)\end{array}$ & Women (\%) & Mean age (years) & $\begin{array}{l}\text { Mean age at onset } \\
\text { (years) }\end{array}$ & $\begin{array}{l}\text { Mean disease } \\
\text { duration (years) }\end{array}$ \\
\hline Rheumatoid arthritis, RF+ & 8104 & 93.4 & 76.2 & 56.1 & 45.7 & 10.3 \\
\hline Rheumatoid arthritis, RF- & 4888 & 77.9 & 77.8 & 55.7 & 47.7 & 7.9 \\
\hline Ankylosing spondylitis & 1486 & 82.8 & 36.1 & 43.2 & 28.5 & 14.5 \\
\hline Other seronegative spondyloarthropathy & 1524 & 80.9 & 64.3 & 43.9 & 35.9 & 7.7 \\
\hline Psoriatic arthritis & 2119 & 86.5 & 55.2 & 48.2 & 39.5 & 8.6 \\
\hline Reactive arthritis & 672 & 48.7 & 58.5 & 38.7 & 35.6 & 3.2 \\
\hline Other arthritides & 2029 & 73.6 & 59.8 & 43.5 & 36.3 & 6.8 \\
\hline Systemic lupus erythematosus & 1211 & 88.3 & 89.5 & 41.8 & 32.2 & 9.6 \\
\hline Scleroderma & 323 & 80.2 & 86.4 & 52.7 & 44.8 & 7.8 \\
\hline Sjögren's syndrome & 453 & 75.5 & 94.7 & 50.8 & 41.2 & 9.3 \\
\hline Other connective tissue diseases & 1287 & 68.0 & 84.1 & 46.8 & 39.9 & 6.9 \\
\hline Polymyalgia rheumatica & 998 & 81.6 & 71.8 & 66.8 & 63.6 & 3.2 \\
\hline Other vasculitides & 559 & 78.1 & 62.8 & 50.1 & 43.7 & 6.2 \\
\hline Total & 25653 & 83.0 & 71.0 & 51.5 & 42.7 & 8.7 \\
\hline
\end{tabular}

at onset, disease duration, and the proportion of cases with definite disease. The proportion of cases with definite disease according to agreed criteria was highest for seropositive RA with $93 \%$ and lowest for reactive arthritis with $49 \%$. The proportion of women was $77 \%$ in RA and $36 \%$ in AS. Sjögren's syndrome with $95 \%$ had the highest proportion of women, followed by SLE with $90 \%$.

The mean disease duration was 10.3 years in seropositive and 7.9 years in seronegative RA. Patients with AS differed from all other groups in having a long mean disease duration (14.5 years).

Figure 2 shows the distribution of the age at onset for patients with selected diagnoses and a disease duration of less than five years (see "Patients and methods" section). The most common age at onset for both AS and SLE was in the twenties. Reactive arthritis had a peak at ages 31-35, whereas RA showed the typical

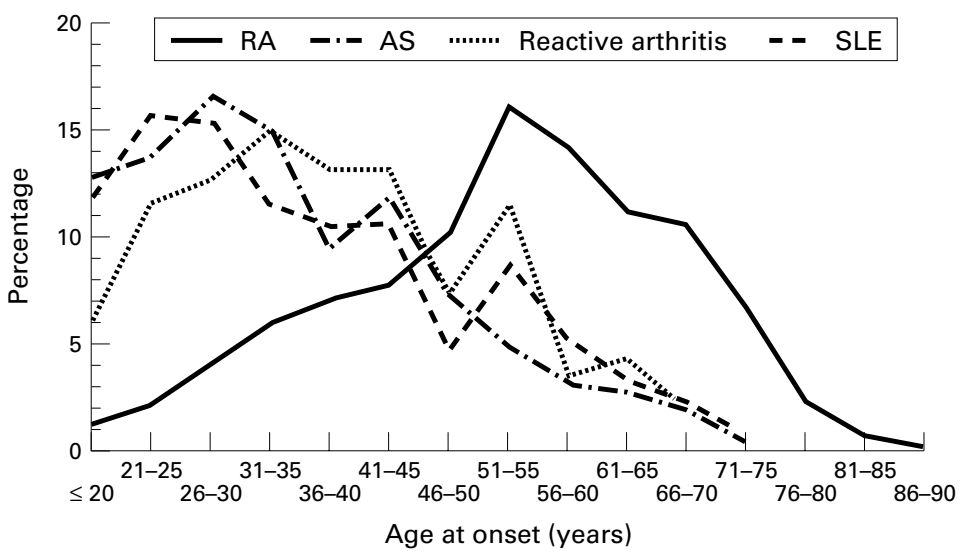

Figure 2 Age at onset distribution for selected diagnoses (disease duration $\leqslant 5$ years; data from 1993 to 1998).

Table 2 Age at onset distribution for recent onset ( $\leqslant 2$ years) $R A, A S$, and SLE (values are percentages, cases from 1993 to 1998)

\begin{tabular}{|c|c|c|c|c|c|c|}
\hline \multirow[b]{2}{*}{ Age at onset } & \multicolumn{2}{|l|}{$R A$} & \multicolumn{2}{|l|}{$A S$} & \multicolumn{2}{|l|}{$S L E$} \\
\hline & Women & Men & Women & Men & Women & Men \\
\hline $15-24$ & 2.5 & 1.4 & 21.5 & 23.7 & 26.3 & 11.3 \\
\hline $25-34$ & 8.2 & 6.1 & 27.3 & 30.1 & 27.9 & 27.4 \\
\hline $35-44$ & 12.3 & 12.3 & 17.7 & 20.2 & 21.2 & 18.9 \\
\hline $45-54$ & 21.6 & 20.2 & 23.0 & 13.8 & 12.7 & 21.7 \\
\hline $55-64$ & 25.4 & 29.3 & 8.1 & 8.5 & 8.8 & 13.2 \\
\hline $65-74$ & 22.4 & 23.7 & 1.4 & 3.5 & 2.9 & 6.6 \\
\hline $74-84$ & 7.1 & 6.4 & 1.0 & 0.3 & 0.3 & 0.9 \\
\hline 85 and above & 0.5 & 0.6 & 0 & 0 & 0 & 0 \\
\hline Total No of cases & 7521 & 2937 & 209 & 326 & 685 & 106 \\
\hline
\end{tabular}

maximum around ages 51-55. The figure also shows that in a considerable proportion of the patients with RA (19\%) disease onset was before the age of 40 .

To enable comparison of the age at onset distribution in our database with incidence data from population studies (see "Discussion"), table 2 shows the ages at onset for patients with RA, AS, and SLE of recent onset ( $\leqslant 2$ years).

The case mix differed considerably depending on the institutional level (table 3): RA comprised only $37 \%$ of the diagnoses of university departments of internal rheumatology but $53 \%$ of those in rheumatology hospitals, $55 \%$ of those in individual practices, and $68 \%$ of those in other units (rehabilitation and orthopaedic hospitals). SLE and other connective tissue diseases were seen more commonly at university departments $(29 \%$ as compared with $19 \%$ in rheumatology hospitals, $13 \%$ in individual practices, and only $8 \%$ in other institutions).

REFERRAL TO A RHEUMATOLOGIST

Most of the patients undergoing treatment in university or other rheumatology hospitals $(91 \%)$ had been referred by a general practitioner or a specialist in individual practice. Referrals from rheumatologists in practices to rheumatology outpatient clinics were rare (only $2.9 \%$ of all cases in rheumatology clinics had been referred by rheumatologists). Patients seeing rheumatologists in individual practices had been referred by a non-specialist doctor in $74 \%$ of the cases.

About two thirds of the patients had seen a rheumatologist within the first year after disease onset (table 4): 64\% in RA, 55\% in psoriatic arthritis, $66 \%$ in SLE, but only $39 \%$ in AS and $50 \%$ in other seronegative spondyloarthropathies. These figures are reflected in differences in the mean disease duration at the first consultation of a rheumatologist: patients with RA first saw a rheumatologist an average of 1.7 years (20 months) after disease onset, whereas in AS the mean disease duration at first visit to a rheumatologist was five years.

The mean time lag between first symptoms and first consultation of a family doctor was three months in RA and 11 months in AS. Patients with SLE first went to see a doctor on an average of six months after symptom onset, 
Table 3 Case mix according to institutional level

\begin{tabular}{|c|c|c|c|c|c|c|c|c|c|c|}
\hline & \multicolumn{2}{|c|}{$\begin{array}{l}\text { University outpatient } \\
\text { clinics }\end{array}$} & \multicolumn{2}{|c|}{$\begin{array}{l}\text { Rheumatogy outpatient } \\
\text { clinics at hospitals }\end{array}$} & \multicolumn{2}{|c|}{ Individual practices } & \multicolumn{2}{|c|}{$\begin{array}{l}\text { Rehabilitation hospitals } \\
\text { and orthopaedic } \\
\text { rheumatology }\end{array}$} & \multicolumn{2}{|l|}{ Total } \\
\hline & No & $\%$ & No & $\%$ & No & $\%$ & No & $\%$ & No & $\%$ \\
\hline RA & 2685 & 37.1 & 4384 & 53.2 & 4369 & 55.3 & 1554 & 68.1 & 12992 & 50.6 \\
\hline AS & 463 & 6.4 & 441 & 5.4 & 481 & 6.1 & 101 & 4.4 & 1486 & 5.8 \\
\hline Reactive arthritis & 294 & 4.1 & 227 & 2.8 & 137 & 1.7 & 14 & 0.6 & 672 & 2.6 \\
\hline Other arthritides & 1725 & 23.8 & 1627 & 19.8 & 1896 & 24.0 & 424 & 18.6 & 5672 & 22.1 \\
\hline SLE & 587 & 8.1 & 335 & 4.1 & 258 & 3.3 & 31 & 1.4 & 1211 & 4.7 \\
\hline \multicolumn{11}{|l|}{ Other conn. tissue } \\
\hline diseases & 1489 & 20.6 & 1219 & 14.8 & 753 & 9.5 & 159 & 7.0 & 3620 & 14.1 \\
\hline Total & 7243 & & 8233 & & 7894 & & 2283 & & 25653 & \\
\hline
\end{tabular}

patients with other vasculitides after four months. Thus for the major part of the time between symptom onset and the first visit to a rheumatologist the patients were receiving non-specialised medical care. Given that for all patients with RA the mean disease duration at first contact with a rheumatologist was 20 months and at first consultation with a doctor was three months, the mean delay in consultation of a specialist was 17 months.

A total of $28 \%$ of all patients were new cases who had been seen in the rheumatology unit for the first time within the previous three months (table 4). The proportion of new cases was highest in seronegative spondyloarthropathies and reactive arthritis and lowest in RA, SLE, and Sjögren's syndrome. Half of these new patients had contacted the rheumatologist within six months of symptom onset ( $48 \%$ in RA and $47 \%$ in SLE).

FREQUENCY OF VISITS TO THE RHEUMATOLOGIST AND TO THE FAMILY DOCTOR

Most of the patients had a non-rheumatologist who mainly treated them for their inflammatory rheumatic condition as well as for other conditions. Only $19 \%$ of the patients with RA (and $21 \%$ of all patients) had not been to their family doctor within the previous three months.

Patients who were treated in university outpatient clinics reported an average number of 5.0 contacts with a rheumatologist, those in hospital outpatient clinics 3.7 , and patients of rheumatologists in individual practices reported an average of 7.0 contacts.

A greater frequency of contact with a rheumatologist is associated with a lower rate of contact with a family doctor: The mean number of visits to a family doctor over the previous three months was 3.6, 4.1, and 3.4 for patients being treated in university settings, hospitals, and individual practices, respectively. If we project these figures to 12 months and add the number of contacts with a rheumatologist in the corresponding settings over the previous year, the results are very similar: 19 doctor visits for patients in university outpatient clinics, 20 for those in hospital outpatient clinics, and 21 for patients recorded by rheumatologists in individual practices.

\section{OCCUPATIONAL SITUATION OF THE PATIENTS}

Of all patients aged $18-60,52 \%$ were still in gainful employment. Table 5 shows the employment situation of men and women with RA, AS, SLE, and vasculitis for selected age groups. Women with RA had an employment rate of $42 \%$, those with AS of $56 \%$. At ages 51-60 only $29 \%$ of all women were still in gainful employment. Men at this age still had an employment rate of about one half. Because $26 \%$ of the women in this age group classified themselves as housewives, the percentage of patients who were early retired was about the same for men and women.

Nevertheless, early retirement in the age group $51-60$ is common in Germany. ${ }^{12}{ }^{13} \mathrm{In}$ 1998 only $51 \%$ of women and $72 \%$ of men in the population were still working at that age. The difference from the population level was $13 \%$ in all women in the database between the ages of 41 and 50 and $22 \%$ in women between ages 51 and 60 . In men it was $11 \%$ for the age group $41-50$ and $23 \%$ for the group aged 51-60.

Table 4 Health services use of the outpatients in the database

\begin{tabular}{llll}
\hline & $\begin{array}{l}1^{\text {st }} \text { visit to rheumatologist } \\
\text { within 1st year of disease } \\
\text { (\% of all patients seen in }\end{array}$ & $\begin{array}{l}\text { Mean (median) disease } \\
\text { duration at 1st visit to a } \\
\text { rheumatologist in months } \\
\text { (all patients) }\end{array}$ & $\begin{array}{l}\text { Percentage of newly } \\
\text { referred patients (<3 } \\
\text { months before registration) }\end{array}$ \\
\hline Rheumatoid arthritis, RF+ & 1998) & $20.2(9)$ & 17.9 \\
Rheumatoid arthritis, RF- & 63.3 & $20.6(8)$ & 24.6 \\
Ankylosing spondylitis & 65.0 & $61.8(34)$ & 32.7 \\
Other seroneg. spondyloarthropathy & 38.5 & $41.2(13)$ & 35.3 \\
Psoriatic arthritis & 49.9 & $28.7(12)$ & 29.5 \\
Reactive arthritis & 55.2 & $8.6(3)$ & 65.4 \\
Other arthritides & 77.8 & $19.4(6)$ & 52.7 \\
SLE & 66.2 & $18.0(6)$ & 18.3 \\
Scleroderma & 66.3 & $30.4(12)$ & 28.8 \\
Sjögren's syndrome & 56.3 & $33.0(12)$ & 18.2 \\
Other connective tissue diseases & 56.4 & $18.8(8)$ & 31.4 \\
Polymyalgia rheumatica & 60.9 & $5.9(3)$ & 35.0 \\
Other vasculitides & 84.4 & $14.4(4)$ & 29.8 \\
Total & 70.7 & $23.0(9)$ & 27.7 \\
\hline
\end{tabular}


Table 5 Employment situation of outpatients in selected diagnostic groups, by age and sex (\% and confidence interval)

\begin{tabular}{|c|c|c|c|c|c|c|c|c|}
\hline & \multicolumn{8}{|c|}{ Rheumatoid arthritis } \\
\hline & \multicolumn{4}{|c|}{ Female $(n=5402)$} & \multicolumn{4}{|l|}{ Male $(n=1594)$} \\
\hline & $18-40$ years & $41-50$ years & $51-60$ years & $18-60$ years & $18-40$ years & $41-50$ years & $51-60$ years & $18-60$ years \\
\hline Employed & $57(54$ to 59$)$ & 56 (53 to 58$)$ & 27 (25 to 29$)$ & 42 (41 to 43$)$ & $76(72$ to 81$)$ & 70 (66 to 75$)$ & $46(43$ to 49$)$ & $58(55$ to 60$)$ \\
\hline Housewife & $19(17$ to 21$)$ & 17 (15 to 19$)$ & 27 (25 to 29$)$ & $23(21$ to 24$)$ & - & - & - & - \\
\hline Retired & 8 (6 to 9$)$ & 17 (15 to 19$)$ & 39 (37 to 40 ) & 25 (24 to 26$)$ & 5 (3 to 8$)$ & $16(12$ to 19$)$ & 45 (42 to 49 ) & $30(28$ to 33$)$ \\
\hline \multirow[t]{4}{*}{ Other } & 17 (15 to 19$)$ & $10(8$ to 12$)$ & $7(6$ to 8$)$ & $10(10$ to 11$)$ & 18 (13 to 22$)$ & $13(10$ to 17$)$ & $9(7$ to 11$)$ & 12 (10 to 13$)$ \\
\hline & \multicolumn{8}{|c|}{ Ankylosing spondylitis } \\
\hline & \multicolumn{4}{|c|}{ Female $(n=409)$} & \multicolumn{4}{|l|}{ Male $(n=738)$} \\
\hline & $18-40$ years & $41-50$ years & $51-60$ years & $18-60$ years & $18-40$ years & $41-50$ years & $51-60$ years & $18-60$ years \\
\hline Employed & 63 (57 to 70$)$ & 56 (47 to 65$)$ & $38(28$ to 48$)$ & 56 (51 to 61$)$ & $70(65$ to 75$)$ & 70 (64 to 77$)$ & $50(42$ to 57$)$ & 65 (61 to 68$)$ \\
\hline Housewife & $16(11$ to 21$)$ & $11(5$ to 17$)$ & 21 (13 to 29$)$ & $16(12$ to 19$)$ & - & - & & - \\
\hline Retired & $3(1$ to 6$)$ & 19 (12 to 27$)$ & 32 (23 to 42$)$ & $14(11$ to 17$)$ & $6(3$ to 8$)$ & 16 (11 to 22$)$ & 37 (30 to 43 ) & $16(14$ to 19$)$ \\
\hline \multirow[t]{4}{*}{ Other } & $18(12$ to 23$)$ & $14(7$ to 20$)$ & 9 (5 to 17$)$ & $15(12$ to 19$)$ & $24(20$ to 29$)$ & $13(8$ to 18$)$ & 13 (9 to 18$)$ & 19 (16 to 22$)$ \\
\hline & \multicolumn{8}{|l|}{$S L E$} \\
\hline & \multicolumn{4}{|l|}{ Female $(n=882)$} & \multicolumn{4}{|l|}{ Male $(n=92)$} \\
\hline & $18-40$ years & $41-50$ years & $51-60$ years & $18-60$ years & $18-40$ years & $41-50$ years & $51-60$ years & $18-60$ years \\
\hline Employed & $54(50$ to 58$)$ & 49 (42 to 57$)$ & $24(18$ to 30$)$ & 47 (43 to 50$)$ & 56 (41 to 69$)$ & 74 (51 to 88 ) & $36(21$ to 54$)$ & 53 (43 to 63 ) \\
\hline Housewife & $14(11$ to 17$)$ & 13 (7 to 18$)$ & $20(14$ to 25$)$ & $15(13$ to 17$)$ & - & - & & \\
\hline Retired & $12(9$ to 15$)$ & $28(21$ to 34$)$ & $50(42$ to 57$)$ & $23(20$ to 26$)$ & $13(6$ to 26$)$ & $26(12$ to 49$)$ & $54(36$ to 70$)$ & 28 (20 to 38$)$ \\
\hline \multirow[t]{4}{*}{ Other } & $20(17$ to 24$)$ & $10(5$ to 14$)$ & 7 (3 to 10$)$ & $15(13$ to 18$)$ & 31 (20 to 46$)$ & - & $11(4$ to 27$)$ & $8(12$ to 28$)$ \\
\hline & \multicolumn{8}{|l|}{ Vasculitides } \\
\hline & \multicolumn{4}{|c|}{ Female $(n=363)$} & \multicolumn{4}{|l|}{ Male $(n=211)$} \\
\hline & $18-40$ years & $41-50$ years & $51-60$ years & $18-60$ years & $18-40$ years & $41-50$ years & $51-60$ years & $18-60$ years \\
\hline Employed & 55 (45 to 65$)$ & 50 (39 to 61$)$ & 29 (23 to 35$)$ & 40 (35 to 45$)$ & 72 (60 to 81$)$ & 74 (60 to 84$)$ & $53(43$ to 62$)$ & $63(57$ to 70$)$ \\
\hline Housewife & $9(5$ to 17$)$ & $15(8$ to 24$)$ & 27 (21 to 33$)$ & $20(16$ to 24$)$ & - & - & & - \\
\hline Retired & $16(10$ to 25$)$ & $20(13$ to 30$)$ & 38 (31 to 45$)$ & $29(24$ to 33$)$ & $16(9$ to 26$)$ & $24(14$ to 30$)$ & $40(30$ to 49$)$ & 29 (23 to 35$)$ \\
\hline \multirow[t]{4}{*}{ Other } & $20(13$ to 29$)$ & $16(7$ to 23$)$ & 7 (2 to 7$)$ & $12(8$ to 15$)$ & 13 (6 to 23$)$ & $2(0$ to 11$)$ & 8 (3 to 13$)$ & $8(4$ to 12$)$ \\
\hline & \multicolumn{8}{|l|}{ All patients } \\
\hline & \multicolumn{4}{|c|}{ Female $(n=10$ 903) } & \multicolumn{4}{|l|}{ Male $(n=4775)$} \\
\hline & $18-40$ years & $41-50$ years & $51-60$ years & $18-60$ years & $18-40$ years & $41-50$ years & $51-60$ years & $18-60$ years \\
\hline Employed & 57 (56 to 59$)$ & $58(56$ to 59$)$ & $29(27$ to 30$)$ & $46(45$ to 47$)$ & 73 (71 to 75$)$ & 76 (73 to 78$)$ & 49 (47 to 52$)$ & 65 (63 to 66$)$ \\
\hline Housewife & $16(15$ to 17$)$ & $16(14$ to 17$)$ & 26 (25 to 27$)$ & $20(19$ to 21$)$ & - & - & - & - \\
\hline Retired & 7 (6 to 8$)$ & $16(15$ to 17$)$ & 38 (36 to 39$)$ & 21 (20 to 22$)$ & $4(3$ to 5$)$ & 13 (11 to 15$)$ & $40(38$ to 42$)$ & $20(19$ to 21$)$ \\
\hline \multirow[t]{3}{*}{ Other } & $20(18$ to 21$)$ & 11 (9 to 12$)$ & $8(7$ to 9$)$ & $13(12,13)$ & $22(20$ to 24$)$ & $12(10$ to 13$)$ & $10(9$ to 12$)$ & $15(14$ to 16$)$ \\
\hline & \multicolumn{8}{|c|}{ General population } \\
\hline & \multicolumn{4}{|l|}{ Female } & \multicolumn{4}{|l|}{ Male } \\
\hline Employed (\%) & 60 & 71 & 51 & 60 & 74 & 87 & 72 & 76 \\
\hline
\end{tabular}

\section{Discussion}

The German rheumatological database was established to observe the processes and outcomes of rheumatological care in the whole of Germany. It has some similarities with the Dutch national database of patients under treatment by rheumatologists. ${ }^{14}$ In both cases participating rheumatologists are provided with analyses of their own data, which enables them to compare their treatment preferences with those of rheumatologists working on the same level of care as well as to gain an overview of general patterns of rheumatological care in their respective countries.

If we compare patients with inflammatory rheumatic diseases registered in the Netherlands in 1993 with those registered in Germany in 1998, the diagnostic patterns are rather similar. In the Netherlands $45 \%$ of all patients with inflammatory rheumatism had RA; the corresponding figure in Germany was $51 \%$. Connective tissue diseases formed a higher proportion in German rheumatology (19\% compared with $13 \%)$, psoriatic arthritis was diagnosed with similar frequency, whereas gouty arthritis, ankylosing spondylitis, and polymyalgia rheumatica were registered more frequently in the Dutch database.

Only 256 cases of juvenile chronic arthritis were recorded, but this low number is due to the fact that the database is maintained in adult rheumatology units. In 1997 German paediatric rheumatologists started a separate database covering more than 2000 cases a year, which are not considered in the present report.

When the age at onset distribution for women with recent onset ( $\leqslant 2$ years) in our data is compared with incidence data from population studies, there is evidence that the arthritis centres - at least for this categorysaw the full spectrum of RA. There is good concordance of our data with incidence data from population studies. ${ }^{15-17}$ There is no relevant difference from the results obtained by 
Symmons et al in the United Kingdom in 1990 $(\mathrm{p}=0.84) .{ }^{15}$ In the light of the results of Hochberg $^{16}$ and the data of Symmons et al, ${ }^{15}$ we possibly missed some male patients aged 75 and above at disease onset. However, the number of men of this age in the population in Germany is only $3.6 \%$ of the male population aged over 14 , significantly lower than in the UK (6.5\%). Therefore, we consider this difference as not important.

Given the high concordance for RA and the unavailability of detailed population data on the age at onset distribution of SLE, AS, or reactive arthritis for white subjects, the results shown in fig 2 and table 2 can at least be used to obtain an idea of the age distribution of incident patients with these diagnoses.

In Germany, there was in the past rather a long delay in the referral to rheumatological care of patients with inflammatory rheumatic diseases. ${ }^{18}$ In RA, a mean disease duration of 3.6 years at the first visit to a rheumatologist and of more than seven years at the first visit to a university department of rheumatology was reported for $1991 .^{18}$ In our data for $1998,75 \%$ of the patients with RA who had contact with a rheumatologist had consulted the specialist within the first two years after disease onset. This is in accordance with data from a rheumatology inception cohort in Edmonton/ Canada, which had $76 \%$ first rheumatology consultations within the first two years of disease.$^{19}$ Very early treatment by rheumatologists ( $<6$ months from symptom onset) in our data occurred in half of all new cases.

The mean time lag between first symptoms and first medical consultation for RA was three months. The delay in referral to a rheumatologist of 17 months after the first medical consultation in RA was much longer than in the study by Chan et al in the US. ${ }^{20}$ They found a median time of eight weeks between the first medical encounter and the first rheumatology consultation for a sample of 54 patients seen at a health maintenance organisation.

The average number of visits to a rheumatologist within the past 12 months was 5.5 in all patients with RA. This is higher than the figure reported in the Edmonton cohort, which had slightly more than two visits per patient a year ${ }^{19}$ and lower than in a community based cohort of patients with at least one contact with a rheumatologist a year. In this study a median number of visits of 7.2 and the best outcomes with seven to 11 visits a year were found. ${ }^{21}$

In accordance with many other studies, ${ }^{22-26}$ participation in the labour force by patients with RA was significantly reduced compared with the total population. We could show that similar handicap concerning employment is experienced by patients with other rheumatic diseases. For the Netherlands, in 1996 a reduction in employment rates at ages $45-64$ of $31 \%$ for men and $9 \%$ for women with RA was found. ${ }^{27}$ In our data the difference from the population for the age group $51-60$ was $26 \%$ in men and $24 \%$ in women. However, a recent study from the Netherlands reports only minor differences $(4.3 \%)$ in labour force participation between patients with RA aged 16-59 treated by rheumatologists, and the general population. ${ }^{28}$ Possibly, this is an indication that more recent treatment strategies in rheumatology might lead to decreased handicap in labour force participation. If this is the case also in Germany, the database should show similar developments in the future.

Our database has several limitations: it includes only patients seen by rheumatologists, it does not give information on the situation of patients who never reach the specialised sector. We do not know how the diseases are diagnosed and treated at the level of the general population. Thus we can only observe changes in the pretreatment of new patients consulting a rheumatologist.

The major question is how representative these patients are of all patients in the population. Probably, the more severe cases will remain in rheumatological care and therefore will be registered as prevalent cases. However, we have evidence that the patients in the database do represent a considerable proportion of the patients in the population: there is one district in Berlin where-owing to a high number of rheumatology practices-more than $50 \%$ of the patients expected in the population are seen by rheumatologists. The age, sex, functional status, and patterns of treatment of these patients do not differ significantly from those of patients in the database. ${ }^{13}$

Compared with the 1970s and 1980s, when very long delays in rheumatological diagnosis and treatment were the reality for most patients with inflammatory rheumatic diseases in Germany, the healthcare situation has improved during the past decade. The time lag until first contact with a rheumatologist has shortened considerably. In the future the arthritis centres will continue in their efforts to bring more patients into specialised care early.

The authors are especially grateful to Drs E Gromnica-Ihle, Berlin, R Rau, Ratingen, and U von Hinüber, Hildesheim, who enrolled more than 1000 patients each.

Supported by a grant from the German Federal Ministry of Health (FB2-433346-8/13).

\section{Appendix: Participating German} collaborative arthritis centres (speakers) Aachen/Köln/Bonn (E Genth), Berlin (J Sieper), Dresden (HE Schröder), Düsseldorf (M Schneider), Erlangen (G Weseloh), Westliches Ruhrgebiet (H Warnatz), Gießen/Bad Nauheim (KL Schmidt), Greifswald (D Köster), Hannover (H Zeidler), Heidelberg (W Eich), Jena (G Hein), Leipzig (H Häntzschel), Lübeck/ Bad Bramstedt (WL Gross), Magdeburg/Vogelsang (J Kekow), Mainz/Bad Kreuznach (R Dreher), München (M Schattenkirchner), Münster (M Gaubitz), Ostwestfalen/Lippe (H Mielke), Regensburg/Bad Abbach (B Lang), Rhein-Main (JP Kaltwasser), Rostock (M Keysser), Saarland (M Pfreundschuh), Südbaden (HH Peter), Südwürttemberg (R Maleitzke).

1 Zeidler H. Modellverbund der BMG-geförderten Rhemazentren (model cooperation of the arthritis centers funded by the Federal Minister of Health). Z Rheumatol 1995;54:215-22.

2 Zink A. Epidemiology of rheumatologic health care in Germany (Epidemiologie der rheumatologischen Versorgung in Deutschland). Z Rheumatol 1995;54:184-91.

3 Zink A, Listing J. Health care status of rheumatic patients in rheumatologic centers 1993 (Versorgungssituation von Rheumakranken in rheumatologischen Zentren im Jahr 1993). Gesundheitswesen 1996;58:648-56. 
4 Arnett FC, Edworthy SM, Bloch DA, McShane DJ, Fries JF, Cooper NS, et al. The American Rheumatism Association 1987 revised criteria for the classification of

5 Steinbrocker O, Traeger CH, Battermann RC. Therapeutic criteria in rheumatoid arthritis. JAMA 1949;140:659-62.

6 Prevoo ML, van Riel PL, van't Hof MA, et al. Validity and reliability of joint indices. A longitudinal study in patients with recent onset rheumatoid arthritis. Br J Rheumatol 1993;32:589-94

7 Prevoo ML, van't Hof MA, Kuper HH, van Leeuwen MA, van de Putte LB, van Riel PL. Modified disease activity scores that include twenty-eight-joint counts. Development and validation in a prospective longitudinal study of patients with rheumatoid arthritis. Arthritis Rheum 1995 38:44-8.

8 Lautenschlaeger J, Mau W, Kohlmann T, Raspe HH, Struve F, Brueckle W, et al. Vergleichende Evaluation einer deutschen Version des Health Assessment Questionnaires (HAQ) und des Funktionsfragebogens Hannover (FFbH) (Comparative evaluation of a German version of the Health Assessment Questionnaire (HAQ) and the Hanover Functional Status Questionnaire (HFSQ)). Z Rheumatol 1997 56:144-55

9 Westhoff G, Listing J, Zink A. Loss of physical independence in rheumatoid arthritis: interview data from a representative sample of patients in rheumatological care. Arthritis Care Research 2000;13:11-22.

10 Norusis MJ. SPSS Advanced Statistics 6.1. Chicago: SPSS Inc, 1994 .

11 Huber PJ. Robust statistics. New York: Wiley, 1981.

12 Statistisches Bundesamt. Bevölkerung und Erwerbstätigkeit. Ergebnisse des Mikrozensus 1998 (Population and employment Results from the microcensus). Wiesbaden: Federal Statistical Office, 1999.

13 Zink A, Braun J, Listing J, Wollenhaupt J. Disability and handicap in rheumatoid arthritis and ankylosing spondylitis - results from the German rheumatological database. J Rheumatol 2000;27:613-22.

14 Miedema HS, van der Linden SM, Rasker JJ, Valkenburg in the Netherlands: the standard diagnosis register of rheuin the Netherlands: the standard diagnosis register of rheumatic diseases. A report an

15 Symmons DPM, Barret EM, Bankhead CR, Scott DGI, Silman AJ. The incidence of rheumatoid arthritis in the United Kingdom: results from the Norfolk Arthritis Register. Br J Rheumatol 1994;33:735-9.

16 Hochberg MC. Changes in the incidence and prevalence of rheumatoid arthritis in England and Wales, 1970-1982. Semin Arthritis Rheum 1990;19:294-302.
17 Dugowson CE, Koepsell TD, Voigt LF, Bley L, Nelson JL, Dailing JR. Rheumatoid arthritis in women. Incidence rates in group health cooperative, Seattle, Washington, 19871989. Arthritis Rheum 1991;34:1502-7.

18 Committee for Regional Rheumatologic Management. Grundzüge einer wohnortnahen kontinuierlichen und kooperativen Versorgung von chronisch Rheumakranken in der Bundesrepublik Deutschland (Principles of continuous and cooperative community management of chronic rheumatic patients in Germany). Z Rheumatol 1994;53:11334.

19 Suarez-Almazor ME, Soskolne CL, Saunders LD, Russell AS. Use of second line drugs for the treatment of rheumatoid arthritis in Edmonton, Alberta. Patterns of prescriptoid arthritis in Edmonton, Alberta. Patterns of prescrip836-43.

20 Chan KWA, Felson DT, Yood RA, Walker AM. The lag time between onset of symptoms and diagnosis of rheumatoid arthritis. Arthritis Rheum 1994;37:814-20.

21 Ward MM. Rheumatology visit frequency and changes in functional disability and pain in patients with rheumatoid arthritis. J Rheumatol 1997;24:35-42.

22 Jantti J, Aho K, Kaarela K, Kautiainen H. Work disability in an inception cohort of patients with seropositive rheumatoid arthritis: a 20 year study. Rheumatology 1999;38: $1138-41$.

23 Doeglas D, Suurmeijer T, Krol B, Sanderman R, van Leeuwen $M$, Rijswijk $M$. Work disability in early rheumatoid arthritis. Ann Rheum Dis 1995;54:455-60.

24 Wolfe F, Hawley DJ. The longterm outcomes of rheumatoid arthritis: work disability: a prospective 18 year study of 823 patients. J Rheumatol 1998;25:2108-17.

25 Sokka T, Kautiainen H, Mottonen T, Hannonen P. Work disability in rheumatoid arthritis 10 years after diagnosis. J Rheumatol 1999;26:1681-5.

26 Albers JM, Kuper HH, van Riel PL, Prevoo ML, van't Hof $\mathrm{MA}$, van Gestel AM, et al. Socio-economic consequences of rheumatoid arthritis in the first years of the disease. Rheumatology 1999;38:423-30.

27 van Jaarsveld $\mathrm{CH}$, Jacobs JW, Schrijvers AJ, van AlbadaKuipers GA, Hofman DM, Bijlsma JW. Effects of rheumatoid arthritis on employment and social participation during the first years of disease in the Netherlands. $\mathrm{Br} J$ ing the first years of disease

28 Chorus AMJ, Miedema HS, Wevers CJ, van der Linden S. Labour force participation among patients with rheumatoid arthritis. Ann Rheum Dis 2000;59:549-54. 